\title{
Modeling of surfactant and surfactant-polymer flooding for enhanced oil recovery using STARS (CMG) software
}

\author{
Sumit Kumar Rai $\cdot$ Achinta Bera $\cdot$ Ajay Mandal
}

Received: 22 May 2013/ Accepted: 24 February 2014/Published online: 13 March 2014

(c) The Author(s) 2014. This article is published with open access at Springerlink.com

\begin{abstract}
Chemical flooding methods are now getting importance in enhanced oil recovery to recover the trapped oil after conventional recovery. Investigation has been made to characterize the surfactant solution in terms of its ability to reduce the surface tension and the interaction between surfactant and polymer in its aqueous solution. A series of flooding experiments have been carried out to find the additional recovery using surfactant and surfactantpolymer slug. Approximately 0.5 pore volume (PV) surfactant (sodium dodecylsulfate) slug was injected in surfactant flooding, while $0.3 \mathrm{PV}$ surfactant slug and $0.2 \mathrm{PV}$ polymer (partially hydrolyzed polyacrylamide) slug were injected for surfactant-polymer flooding. In each case, chase water was used to maintain the pressure gradient. The present work sought to determine whether or not a commercially available simulator could accurately simulate results from core flooding experiments. The adherence to physically realistic input values with respect to experimentally derived parameters was of primary importance during the development of the models. When specific values were not available for certain simulation parameters, a reasonable range of assumptions was made and both the water cut and cumulative oil production were successfully matched. Ultimately, understanding how to simulate the surfactant and polymer behavior on a core scale will improve the ability to model polymer floods on the field scale.
\end{abstract}

Electronic supplementary material The online version of this article (doi:10.1007/s13202-014-0112-3) contains supplementary material, which is available to authorized users.

S. K. Rai · A. Bera · A. Mandal $(\bowtie)$

Department of Petroleum Engineering, Indian School of Mines, Dhanbad 826 004, India

e-mail: mandal_ajay@hotmail.com
Keywords Enhanced oil recovery - Surfactant flooding · Surfactant-polymer flooding · STARS (CMG) software · Simulation and modeling

\section{Introduction}

Oil production has been deliberately reduced day by day, and it has resulted in serious oil crisis accompanied by a general increase in the oil price. This in turn has forced the oil industry to recover oil from more complicated areas, where the oil is less accessible, by means of advanced recovery techniques. After primary and secondary methods, two-thirds of the original oil in place (OOIP) in a reservoir is not produced and still pending for recovery by efficient enhanced oil recovery (EOR) methods. EOR methods can be categorized into three main processes such as thermal oil recovery, miscible flooding, and chemical flooding (Taber et al. 1979; Shandrygin and Lutfullin 2008). Chemical flooding methods are considered as a special branch of EOR processes to produce residual oil after water flooding. These methods are utilized in order to reduce the interfacial tension, to increase brine viscosity for mobility control, and to increase sweep efficiency in tertiary recovery.

Surfactants are considered as good enhanced oil recovery agents since 1970s because it can significantly lower the interfacial tensions and alter wetting properties (Healy and Reed 1974; Cayias et al. 1976). Displacement by surfactant solutions is one of the important tertiary recovery processes by chemical solutions. The addition of surfactant decreases the interfacial tension between crude oil and formation water, lowers the capillary forces, facilitates oil mobilization, and enhances oil recovery. The surfactant is dissolved in either water or oil to form microemulsion 
which in turn forms an oil bank (Bera et al. 2011). The formation of oil bank and subsequent maintenance of sweep efficiency and pressure gradient by injection of polymer and chase water increase the oil recovery significantly (Hill et al. 1973). The idea of injecting surfactant solution to improve imbibitions recovery was proposed for fractured reservoirs (Michels et al. 1996) and carbonaceous oil fields in the United States (Flumerfelt et al. 1993). The effects of capillary imbibitions and lowering of IFT using surfactant slug have been reported by many researchers (Keijzer and De Vries 1990).

It is well known that use of polymer increases the viscosity of the injected water and reduces permeability of the porous media, allowing for an increase in the vertical and areal sweep efficiencies, and consequently, higher oil recovery (Needhan and Peter 1987). The main objective of polymer injection is for mobility control, by reducing the mobility ratio between water and oil. The reduction in the mobility ratio is achieved by increasing the viscosity of the aqueous phase. Another main accepted mechanism of mobile residual oil after water flooding is that there must be a rather large viscous force perpendicular to the oil-water interface to push the residual oil. This force must overcome the capillary forces retaining the residual oil, move it, mobilize it, and recover it (Guo and Huang 1990). The injection of polymer helps to propagate the oil bank formed by surfactant injection by increasing the sweep efficiency. Austad et al. (1994) reported that significant improvements can be obtained by co-injecting surfactant and polymer at a rather low chemical concentration.

It is now important to simulate the experimental results of chemical flooding for design or optimization to calculate the decision variables like cumulative oil recovery factor and net present value. Before any simulation work could take place, a simulator had to be selected. There were two main qualities that were sought after when deciding which simulator was most applicable. First, it was necessary that the simulator had the capacity and the functionalities necessary for modeling the polymer behavior of interest. For example, since the degradation behavior was of particularly important, it was necessary that the selected simulator could model this behavior. It was also desirable for the simulator to be commonly used within the industry. Since the ultimate purpose of conducting the polymer experiments was to gain a better understanding of the polymer behavior for what would eventually be field purposes, it is also important that a commonly available simulator could model the experimental findings.

The three main simulators that were investigated for potential use were Eclipse by Schlumberger, STARS created by CMG, and UTCHEM that has been created for research application at the University of Texas at Austin. The ability of UTCHEM to model a polymer solutions shear-thickening behavior had already been demonstrated by Delshad et al. (2008). Other attractive features of this simulator included the availability of the source code, its specialized ability to model laboratory-scale experiments, and the fact that it was specially designed to model very specific and complex chemical and polymer behavior. The obvious downfall of this simulator is the fact that it is not commonly used outside of the academic realm.

The Eclipse simulator is by far one of the most wellknown reservoir simulation tools in the petroleum industry. Because it is so commonly used in the industry for field applications, it could have been an ideal simulator for modeling the experimental results. Unfortunately, this very popular simulator did not contain the technical functionalities required to model the recent experimental findings that were the focus of this work. At the time of the investigation, the polymer viscosity-related capabilities of the Eclipse simulator were restricted to shear-thinning behavior. Although the simulator also had the capacity to model salinity effects, adsorption behavior, and polymer concentration mixing behavior, without the ability to model the shear-thickening and degradation regimes, a successful simulation could not be produced.

The final simulation tool that was considered and subsequently selected to model the experimental data was the STARS simulator by CMG. This simulator, which is implemented by multiple companies in the petroleum industry, is known for its ability to model both laboratoryand field-scale models while also having the capability to handle complicated chemical behavior. One of the main attractive features of this simulator was option to input the polymer apparent viscosity in a tabular format. Although it was not certain from the outset, the hope was that the tabular input would be able to handle all four flow regimes if necessary. Best of our knowledge, few articles have been published using STARS (CMG) software till now (Santos et al. 2011; Chaipornkaew et al. 2013). Several research works based on the modeling of chemical flooding using different simulation techniques have been published since 1970s. Pope and Nelson (1978) developed a chemical flood simulator (one-dimensional and compositional) to determine the additional oil recovery as a function of different variables. Paul et al. (1982) used a simple model for prediction of micellar/polymer flooding. Bhuyan et al. (1990) presented a generalized model for high $\mathrm{pH}$ chemical floods. Vaskas (1996) developed an economical model for evaluation for chemical flooding. Han et al. (2007) developed a compositional chemical flooding simulator for surfactantpolymer flooding. Fathi Najafabadi et al. (2009) developed 
a simulator for surfactant phase behavior, which is very much important in surfactant flooding.

In the present study, a series of flooding experiments have been carried out to find the additional recovery using surfactant and surfactant-polymer slug. It was followed by a successful simulation using STARS (CMG) software, and results were matched. Through a methodical approach used to identify the best input values, simulation models were created for both surfactant flooding and surfactant-polymer flooding which produced results that were well matched with the experimental data. With these models, both the water cut and cumulative oil production were successfully matched. Ultimately, understanding how to simulate the surfactant and polymer behavior on a core scale will improve the ability to model surfactant and surfactantpolymer floods on the field scale.

\section{Experimental section}

\section{Materials used}

Sodium dodecylsulfate (SDS) (approximately $99 \%$ purity) was used as surfactant, and commercial grade partially hydrolyzed polyacrylamide (PHPA) used as polymer. SDS $(\mathrm{C} 12 \mathrm{H} 24 \mathrm{SO} 4 \mathrm{Na}, \mathrm{MW}=288.38)$ was purchased from Central Drug House (P) Ltd., India, and PHPA (av. mol. wt. $=3,000,000)$ from SNF Floerger, France. $\mathrm{NaCl}$ with $98.5 \%$ purity was purchased from Qualigens Fine Chemicals, India. The aqueous solutions of surfactant and polymer were always freshly prepared to avoid degradation and then stirred with the help of Remi Magnetic Stirrer. The appropriate quantity of anionic surfactant, SDS and polymer, PHPA were mixed carefully for about 15 min for the surfactant-polymer flooding experiments. For the simulation purpose, the experiments that utilized $0.1 \mathrm{wt} \%$ SDS concentration and 2,000 ppm PHPA were considered.
Flooding procedure

All the experiments have been completed by using sand packs in the laboratory. The experimental apparatus is composed of a sand-pack holder, cylinders for chemical slugs and crude oil, positive displacement pump, and measuring cylinders for collecting the samples. The details of the schematics of apparatus are shown in Fig. 1. The displacement pump is one set of Teledyne Isco syringe pump. Control and measuring system is composed of different pressure transducer and a Pentium IV computer. The physical model is homogeneous sand-packing model vertically positive rhythm. The model geometry size is $l=35 \mathrm{~cm}$ and $r=3.5 \mathrm{~cm}$.

Sand-pack flood tests were employed by (1) preparing uniform sand packs, 60-100 mesh sand was cleaned and washed with $1 \%$ brine. Then, the sands were poured into the core holder that was vertically mounted on a vibrator and filled with $1.0 \mathrm{wt} \%$ brine. The core holder was fully filled at a time and was vibrated for $1 \mathrm{~h}$; (2) the wet packed sand pack was flooded with brine, the absolute permeability $\left(k_{\mathrm{w}}\right)$ is calculated; (3) then, sand pack was flooded with the crude oil at 800 psig to irreducible water saturation. The initial water saturation was determined on the basis of mass balance; (4) water flooding was conducted horizontally at a constant pressure, and the same injection flow rate was used for all the displacement tests of this study; (5) After water flooding, $\sim 0.5 \mathrm{PV}$ surfactant in case of surfactant flooding and $\sim 0.3 \mathrm{PV}$ surfactant followed by $\sim 0.2$ PV polymer buffer (surfactant-polymer flooding) were injected followed by $\sim 2.0 \mathrm{PV}$ water injection as chase water flooding.

The effective permeability to oil $\left(k_{\mathrm{o}}\right)$ and effective permeability to water $\left(k_{\mathrm{w}}\right)$ were measured at irreducible water saturation $\left(S_{\mathrm{wi}}\right)$ and residual oil saturation $\left(S_{\text {or }}\right)$, respectively, using Darcy's law equation. The permeability of the sand packs was assessed with the Darcy equation, Eq. 1, for
Fig. 1 Schematic of experimental setup for flooding experiments in sand packs

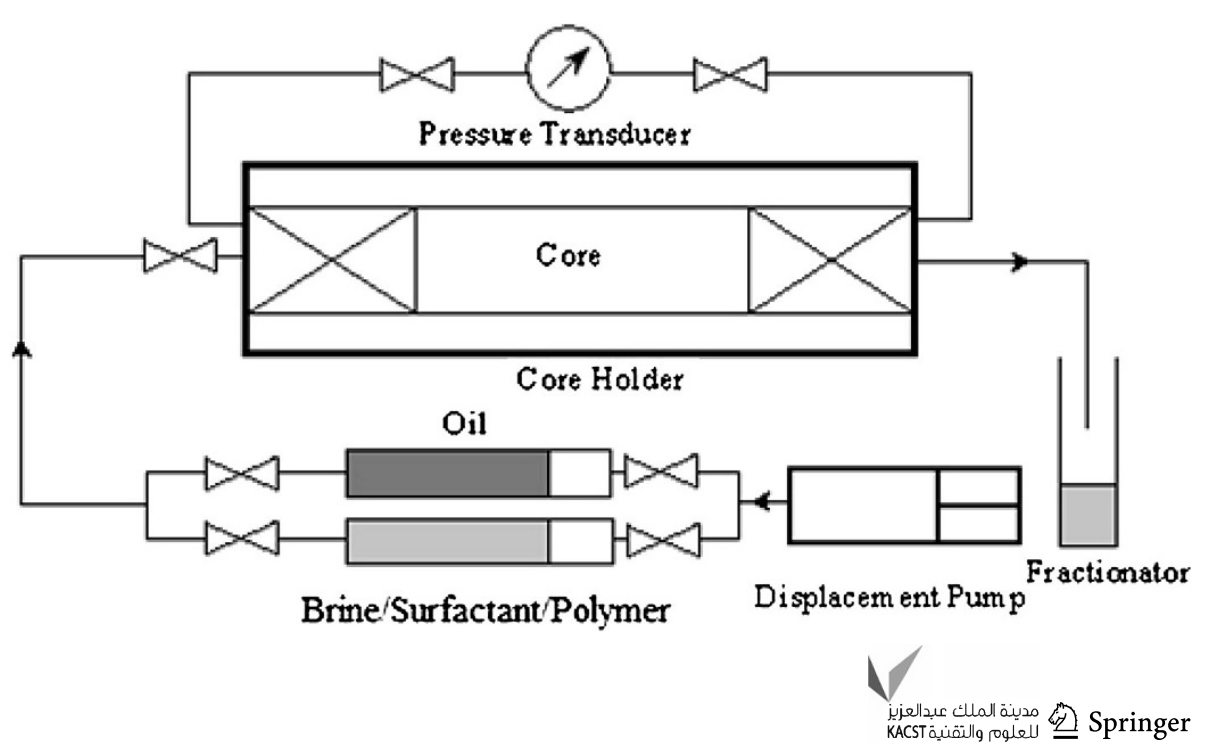


fluid flow in porous materials. For a horizontal linear system, flow rate is related with permeability as follows:

$q=\frac{k A}{\mu} \frac{\mathrm{d} p}{\mathrm{~d} x}$

where $q$ is the volumetric flow rate $\left(\mathrm{cm}^{3} / \mathrm{s}\right), A$ is the total cross-sectional area of the sand pack $\left(\mathrm{cm}^{2}\right), \mu$ is the fluid viscosity (cP), $\frac{\mathrm{d} p}{\mathrm{~d} x}$ is the pressure gradient $(\mathrm{atm} / \mathrm{cm})$, and $k$ is the permeability in Darcy.

Initial oil content, oil recovery factor of secondary and tertiary EOR methods, and residual oil saturation were calculated by material balance during flooding experiments.

The recovery factor is obtained by summing up the amounts of oil recovered in each step (secondary and tertiary oil displacement process) and is expressed in percentage $(\%)$ as follows:

$\mathrm{RF}_{\text {Total }}=\mathrm{RF}_{\mathrm{SM}}+\mathrm{RF}_{\mathrm{TM}}$

where $\mathrm{RF}_{\text {Total }}=$ total recovery factor $(\%), \mathrm{RF}_{\mathrm{SM}}=$ recovery factor obtained by secondary method $(\%)$, and $\mathrm{RF}_{\mathrm{TM}}=$ recovery factor obtained by tertiary method (\%).

Table 1 Fluid and core flood properties in case of surfactant flooding

\begin{tabular}{ll}
\hline Core ID & Sand pack \\
\hline Diameter and length & $7 \mathrm{~cm}, 35 \mathrm{~cm}$ \\
Porosity and permeability & $0.38,1,234 \mathrm{mD}\left(k_{\mathrm{w}}\right)$ \\
Initial oil saturation & 0.809 \\
Irreducible oil saturation & 0.202 \\
Surfactant used & SDS \\
Surfactant concentration & $0.1 \mathrm{wt} \%$ \\
\hline
\end{tabular}

Simulation of surfactant and surfactant-polymer flooding

First, the experiments and the simulation procedure for surfactant flooding and surfactant-polymer flooding will be described. The core flooding experiment carried out by cairn energy for ASP introduction in their Mangala Field was studied for a better understanding of simulation procedure (Pandey et al. 2008). It will be followed by the results and discussion section. There are several assumptions and equations were used during the simulation study. The assumptions and different equations used in the simulation have been supplied as supplementary documents.

\section{Simulation of surfactant flooding}

For the present study, the surfactant concentration was kept $0.1 \mathrm{wt} \%$. The surfactant slug was injected when water cut reached $\sim 95 \%$ during water flooding. For surfactant flooding, the fluid and sand-pack properties have been given in Table 1.

The sand-pack cores were modeled with 10 blocks each for surfactant flooding (Fig. 2). Thus, a Cartesian grid was prepared in surfactant flooding system. Injection and production wells were located in first block and tenth block, respectively. Porosity map in case of surfactant flooding has been depicted in Fig. 3.

Components were added in the component section with their respective properties. First of all, a water flooding simulation was carried out till the water cut reached $95 \%$. It took $14 \mathrm{~min}$ to complete this process. After $14 \mathrm{~min}$, surfactant flooding was introduced with proper constraint change under the well section. At this stage, $0.5 \mathrm{PV}(60 \mathrm{ml})$
Fig. 2 Cartesian grid formulation for surfactant flooding

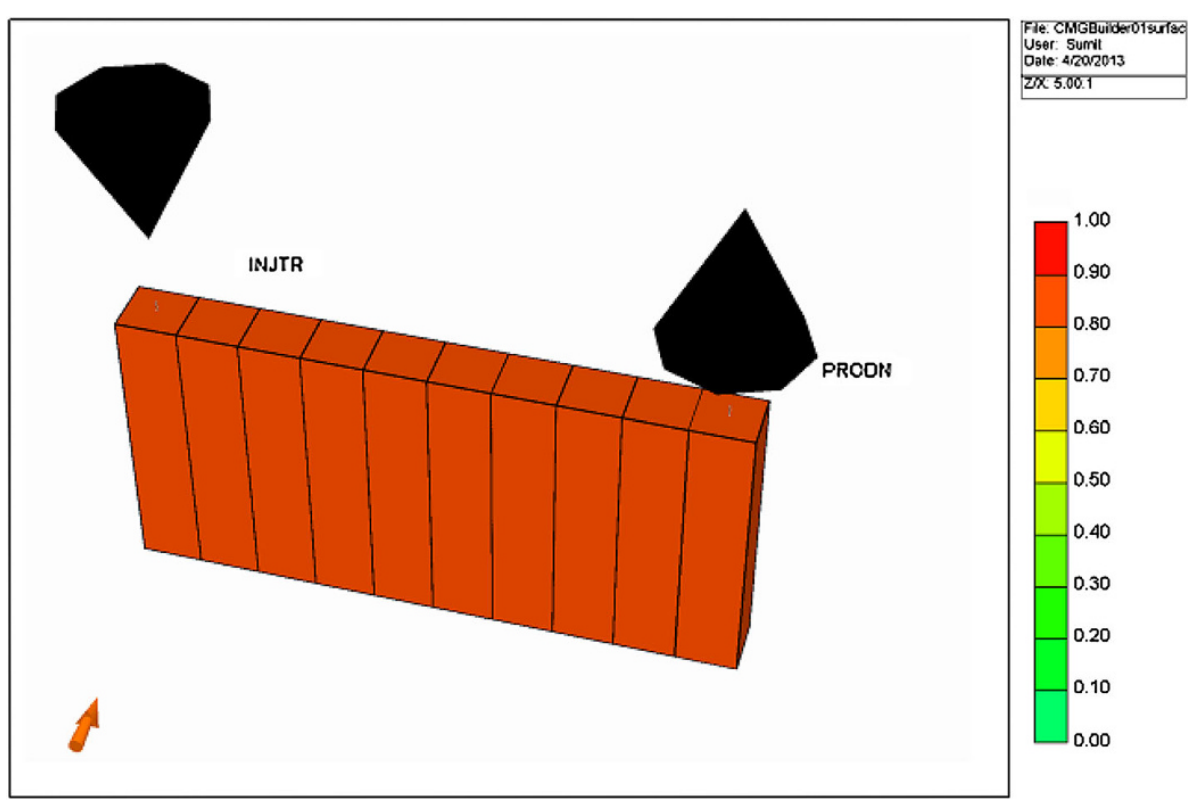


Fig. 3 Porosity map in case of surfactant flooding

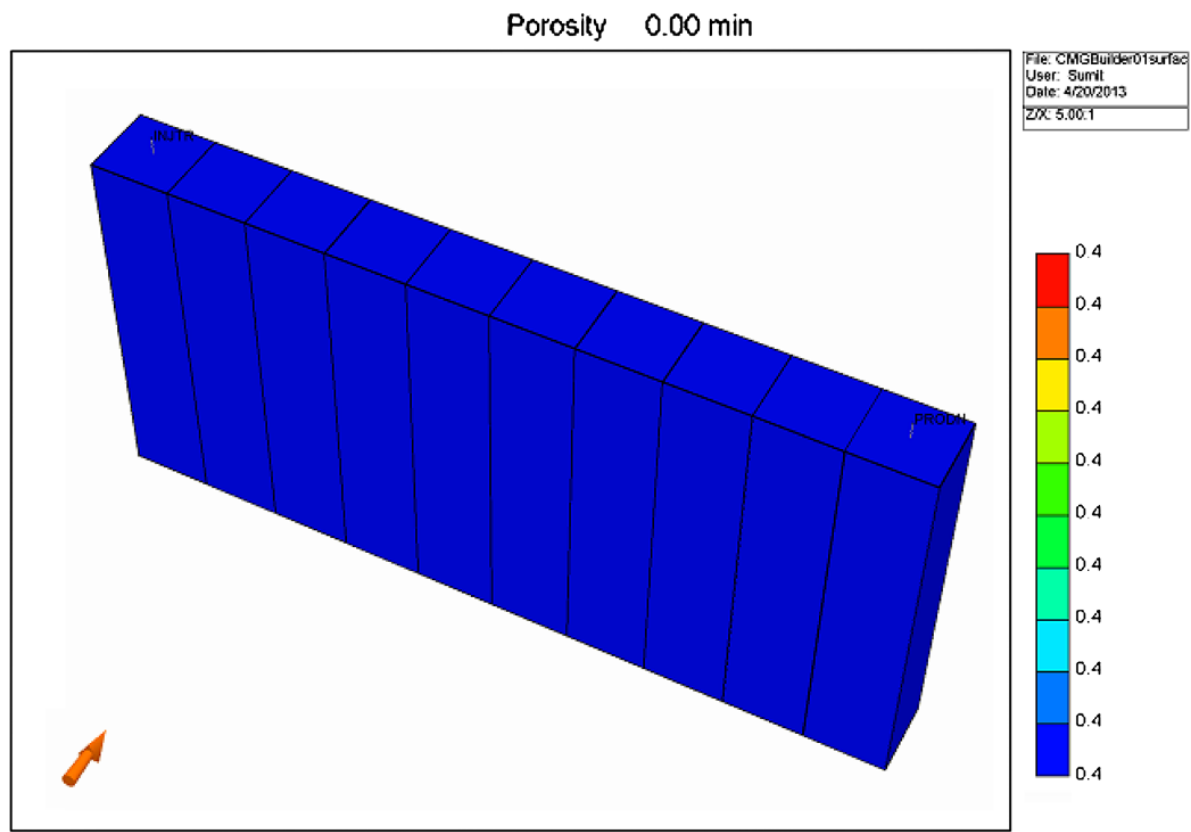

Table 2 Fluid and core flood properties in case of surfactant-polymer flooding

\begin{tabular}{ll}
\hline Core ID & Sand pack \\
\hline Diameter and length & $7 \mathrm{~cm}, 35 \mathrm{~cm}$ \\
Porosity and permeability & $0.368,1,224 \mathrm{mD}\left(k_{\mathrm{w}}\right)$ \\
Initial oil saturation & 0.85 \\
Irreducible oil saturation & 0.229 \\
Surfactant used & SDS \\
Surfactant concentration & $0.1 \mathrm{wt} \%$ \\
Polymer used & PHPA \\
Polymer concentration & $2,000 \mathrm{ppm}$ \\
\hline
\end{tabular}

of surfactant slug was introduced in the sand pack. After completion of surfactant flooding, chase water was used in 20th minute. Simulation was run for a total of $33 \mathrm{~min}$. Injection rate constraint was fixed at $10 \mathrm{ml} / \mathrm{min}$.

Simulation of surfactant-polymer flooding

Following table lists (Table 2), the important fluids and core flood conditions are used for surfactant-polymer flooding.

The same grid pattern was used as in case of surfactant flooding, i.e., $10 \times 1 \times 1$ (Fig. 4). The grid size in $X$ direction was fixed at $3.5 \mathrm{~cm}$. Grid thickness was taken
Fig. 4 Cartesian grid formulation for surfactantpolymer flooding

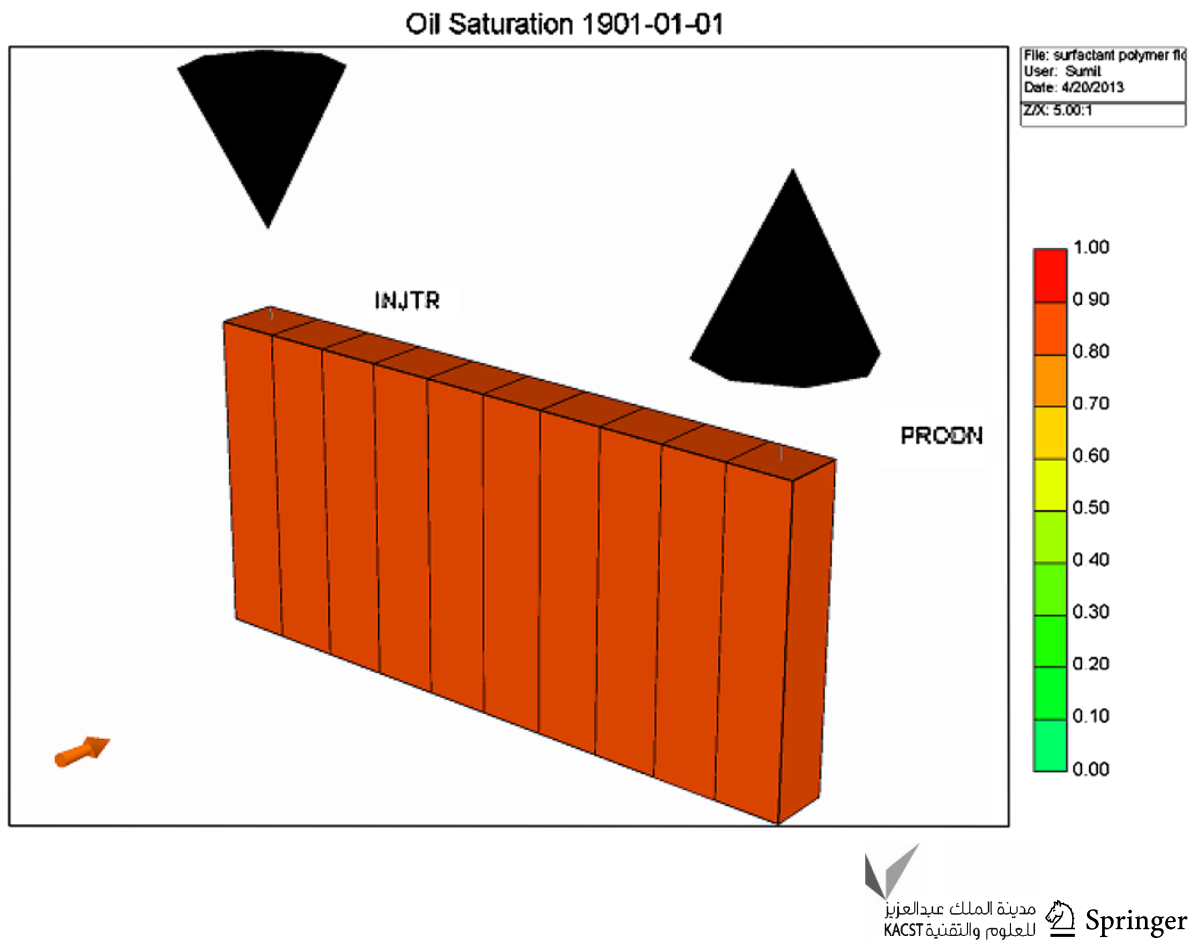


Fig. 5 Oil saturation map at the start of water flooding in case of surfactant flooding

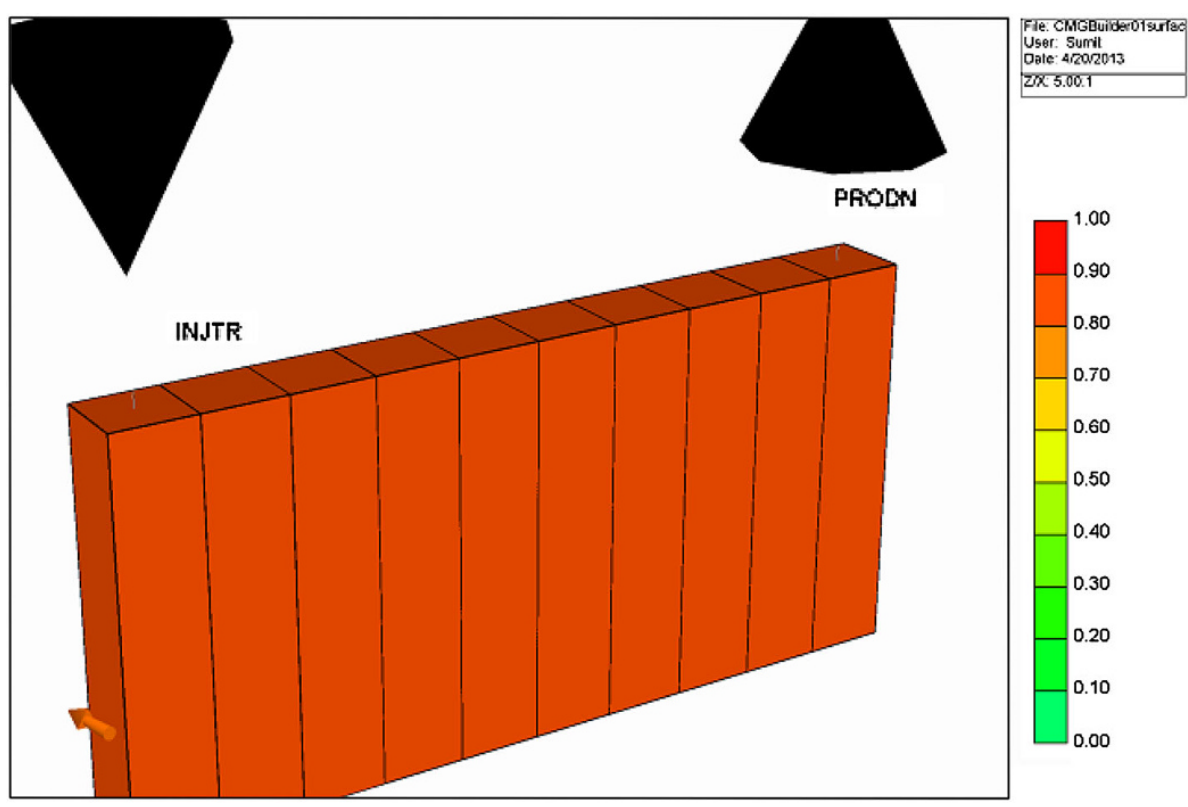

Fig. 6 Oil saturation map just before surfactant slug injection

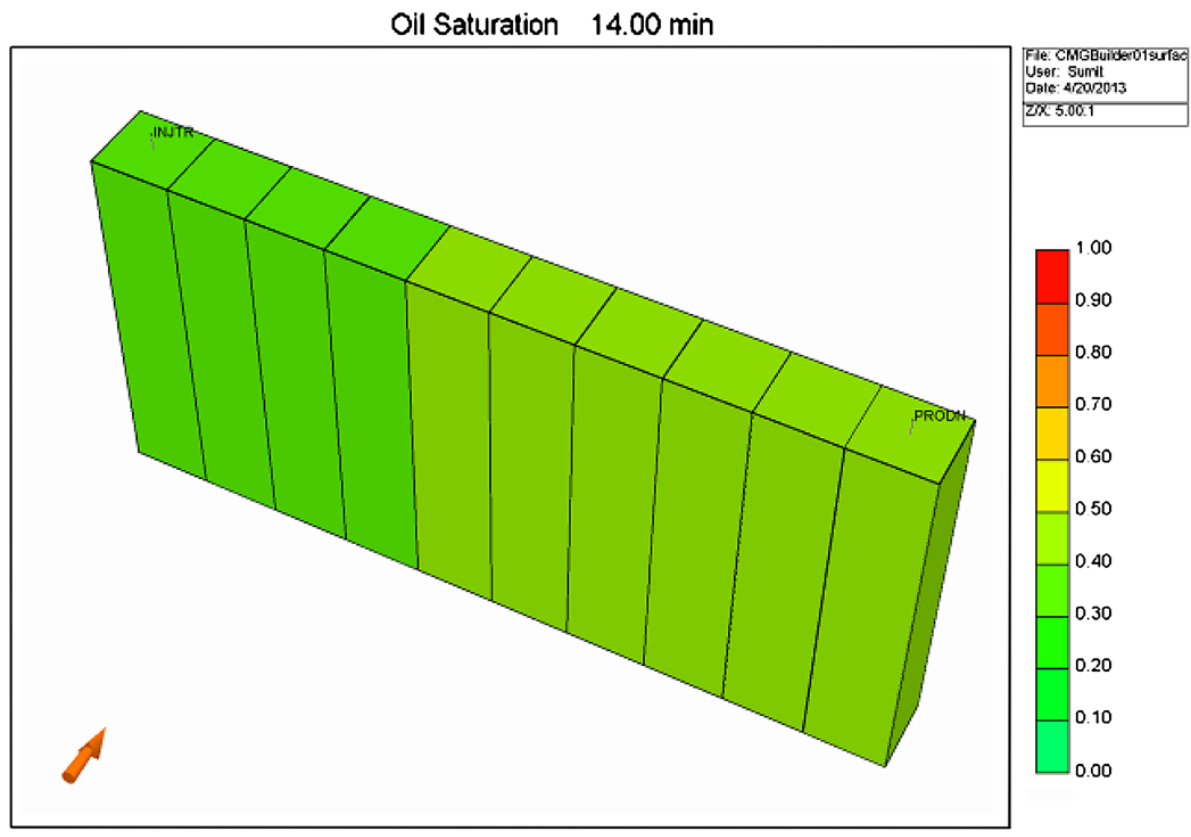

to be $7 \mathrm{~cm}$. Injection and production wells were located in first block and tenth block, respectively. The porosity map for surfactant-polymer flooding system is same as surfactant flooding system as shown in Fig. 3.

Components were added in the component section with their respective properties. First of all, a water flooding simulation was carried out till the water cut reached $95 \%$. It took $18 \mathrm{~min}$ to complete this process. After $18 \mathrm{~min}$, surfactant-polymer flooding was introduced with proper constraint change under the well section. After completion of surfactant-polymer flooding, chase water was used in 24th minute. Simulation was run for a total of $50 \mathrm{~min}$. Injection rate constraint was fixed at $10 \mathrm{ml} / \mathrm{min}$.

\section{Results and discussion}

\section{Surfactant flooding}

Oil saturation maps were generated for three different times: (1) at the start of water flooding (2) at the end of water flooding and start of surfactant flooding, and (3) at the end of simulation.

At the start of water flooding, the oil saturation map shows a uniformity overall the grid (Fig. 5). This represents initial oil saturation. Now, water flooding is started into sand pack. It first pushes the oil near the injector well (in first grid) toward the producer well (in last grid). So, 
Fig. 7 Oil saturation map at the end of simulation in case of surfactant flooding

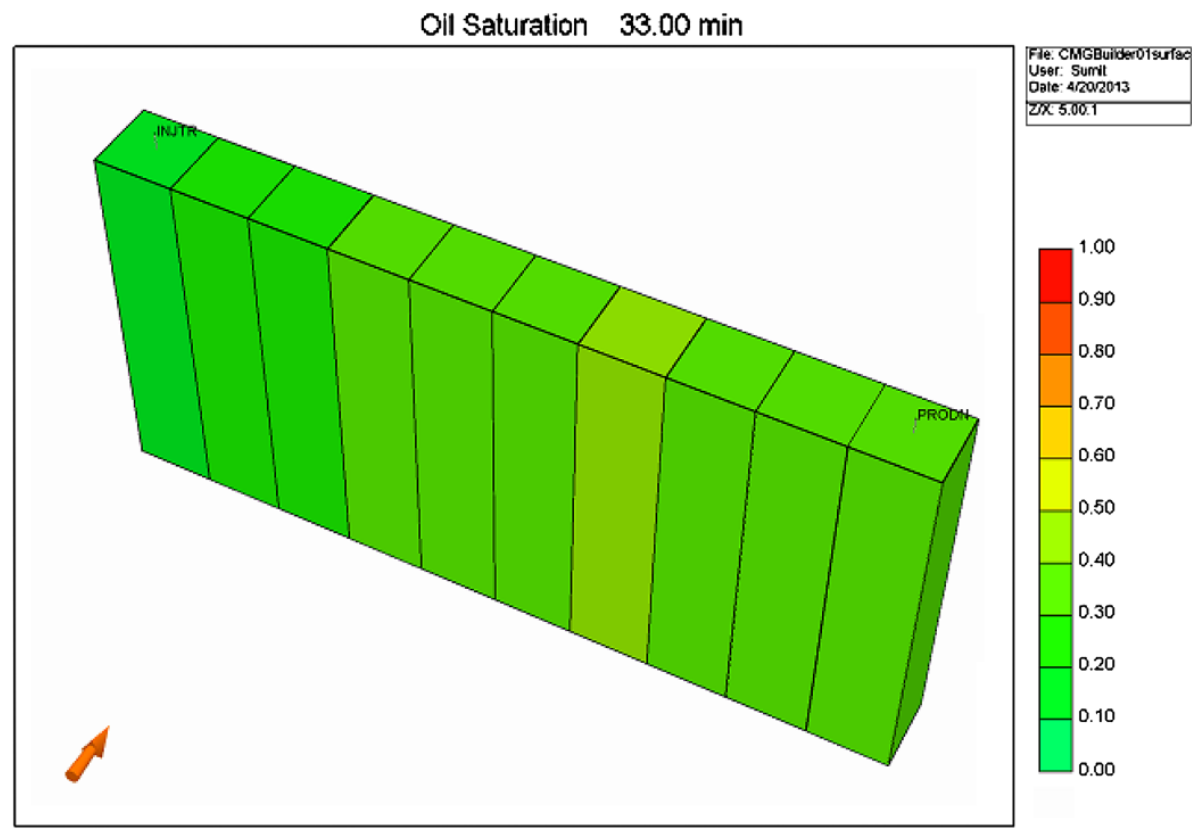

Fig. 8 Plot of water cut and cumulative oil with time in case of surfactant flooding

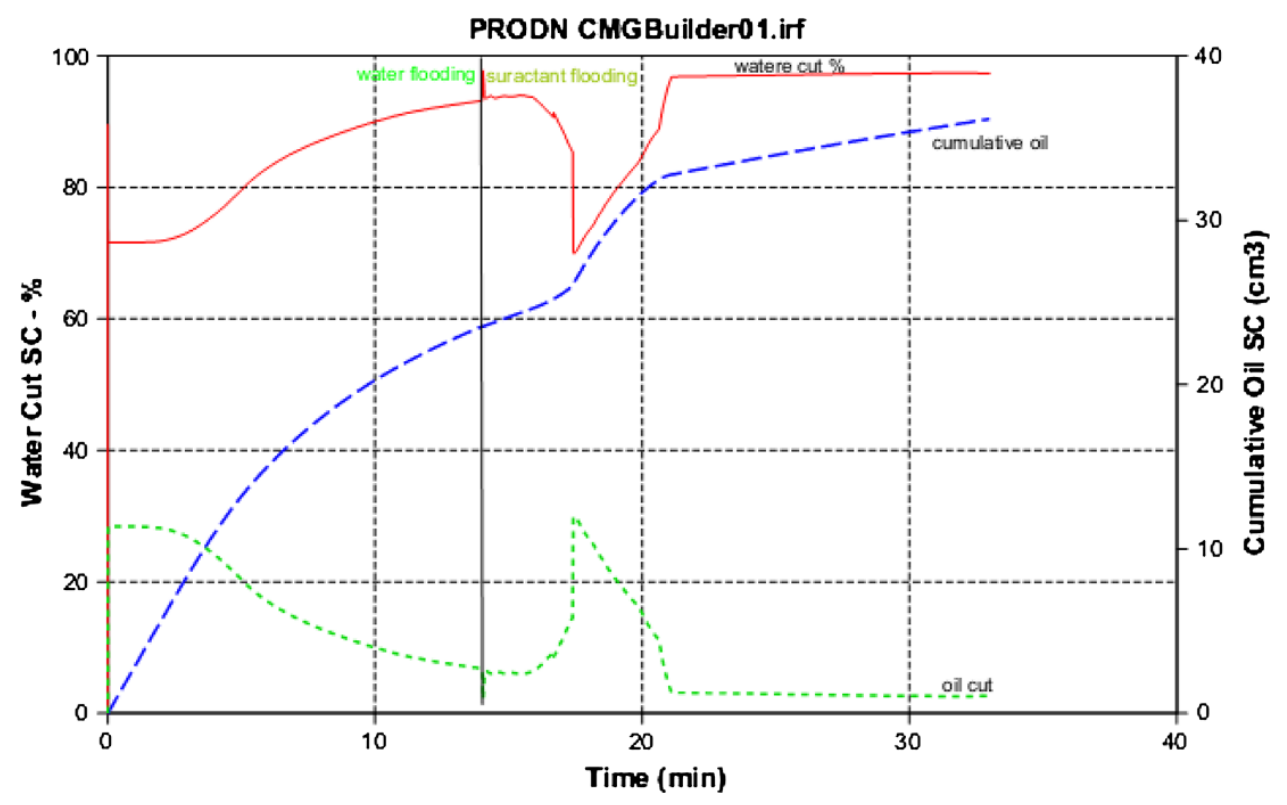

after completion of water flooding (i.e., when water cut reaches $95 \%$ ), the oil saturation map looks like Fig. 6. It has been noticed from Fig. 6 that sweeping of oil is nonhomogenous in the sand packs. Maximum oil swept belongs to the region near injector well. At this juncture, surfactant flooding is introduced into the system. It improves the sweep efficiency by IFT reduction mechanism, and now, oil far away from the injector well is also pushed to the producer well (Fig. 7).

Figure 8 shows the plot of water cut and cumulative oil versus time which reflects the effects of surfactant on the additional oil recovery and how it reduces water cut. With the introduction of water flooding in the sand pack, water cut increases progressively resulting in a decreasing oil cut. By 14th minute, water cut has reached to $95 \%$. At this point, surfactant slug has been introduced for the surfactant flooding. Figure 8 reflects that this leads to a decrease in water cut and increased oil cut and also cumulative oil increases sharply. A second plot (Fig. 9) of water cut and cumulative oil versus pore volume injected reflects the same. Initial oil saturation in the sand pack was found to be $102 \mathrm{ml}$ by volume. According to Fig. 8, total oil recovered at the end of water flooding is $22 \mathrm{ml}$. After surfactant flooding, total oil recovered is $40 \mathrm{ml}$ (after injection chase water). Thus, the additional recovery using surfactantpolymer flooding is $(40-22) / 102=17.65 \%$. The 
Fig. 9 Plot of water cut and cumulative oil with pore volumes injected in case of surfactant flooding
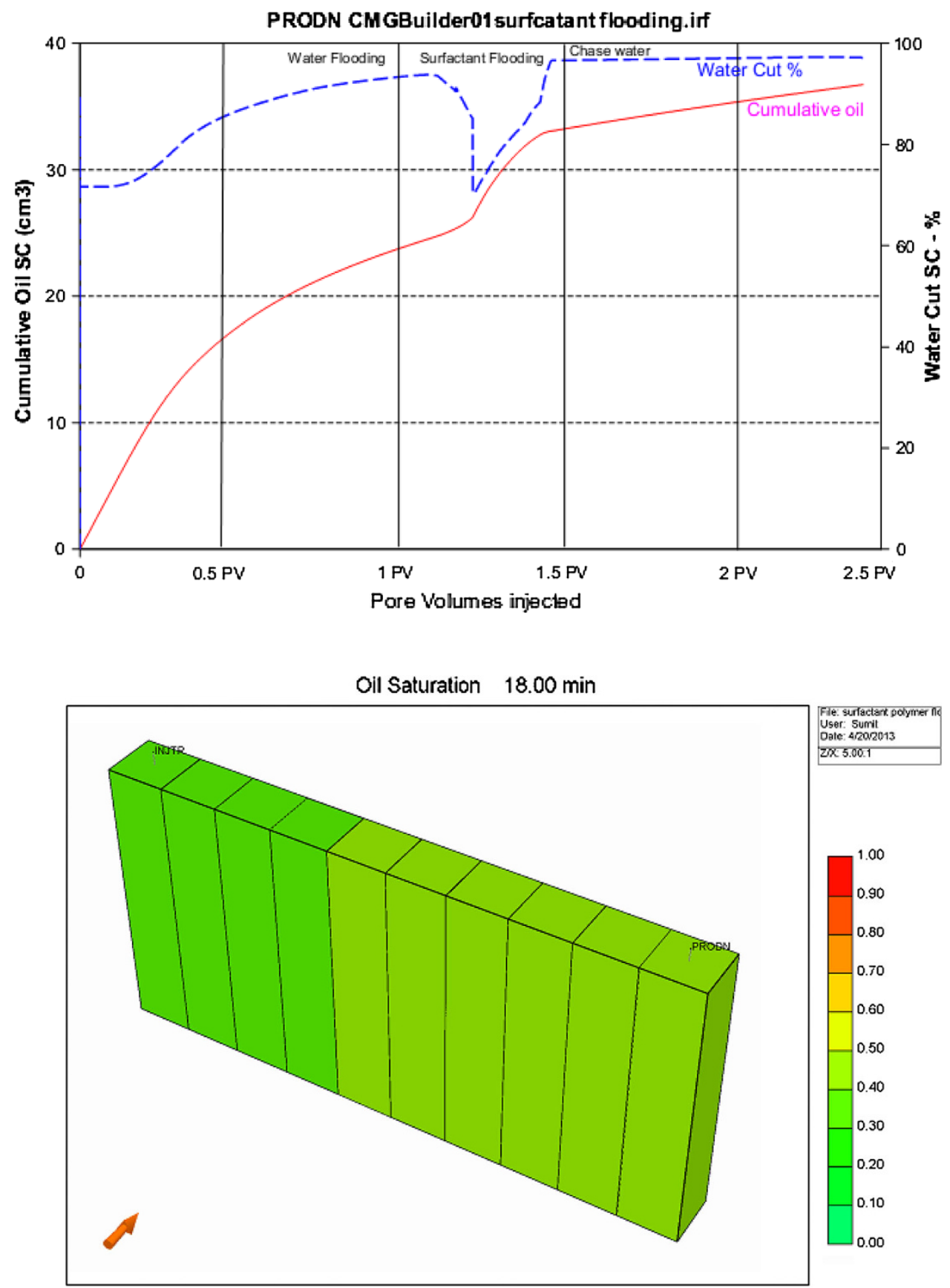

Fig. 10 Oil saturation map just before surfactant-polymer slug injection experimental value shows additional recovery to be $18 \%$ of OOIP.

\section{Surfactant-polymer flooding}

Like the previous case, oil saturation maps were generated for three different times: (1) at the start of water flooding, (2) at the end of water flooding and start of SP flooding, and (3) at the end of simulation.

Figure 10 shows that how oil saturation map changes with different times. At the start of water flooding, the oil saturation map shows a uniformity overall the grid. This represents initial oil saturation. Now, water flooding is started into sand pack. It first pushes the oil near the injector well (in first grid) toward the producer well (in last grid). So, after completion of water flooding (i.e., when water cut reaches to $95 \%$ ), the oil saturation map looks like Fig. 10. The non-homogenous sweeping of oil in the sand packs is very clear from Fig. 10. Maximum oil swept belongs to the region near injector well. At this juncture, surfactantpolymer slug is introduced into the system. It improves the sweep efficiency with the synergistic contribution of IFT 
Fig. 11 Oil saturation map at the end of simulation in case of surfactant-polymer flooding
Fig. 12 Plot of water cut and cumulative oil with time in case of surfactant-polymer flooding
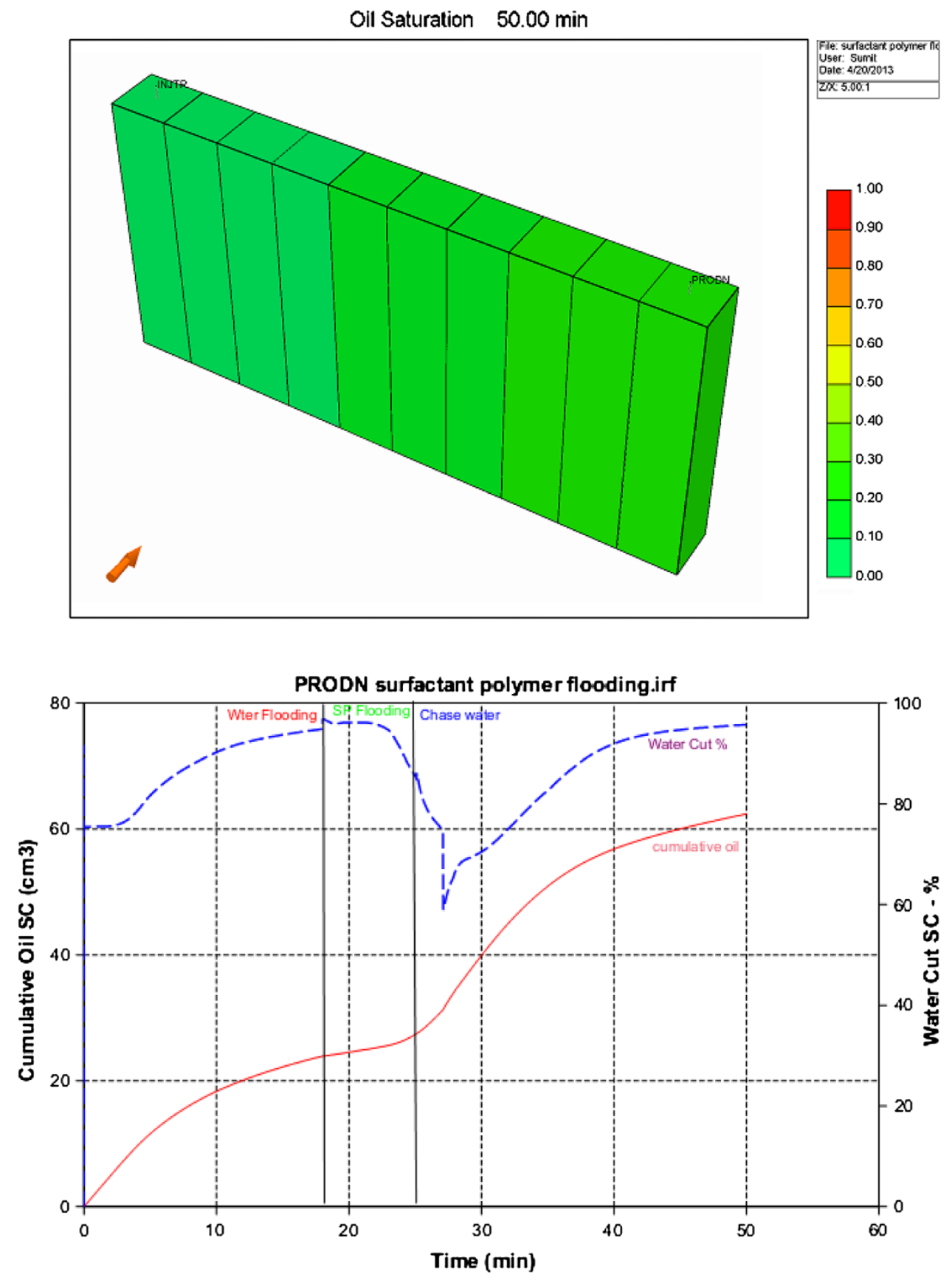

reduction by surfactant. Oil far away from the injector well is also pushed to the producer well (Fig. 11).

Figure 12 shows the water cut and cumulative oil versus time. The effects of surfactant and polymer concentration on the additional oil recovery and how it reduces water cut. With the introduction of water flooding in the sand pack, water cut increases progressively and resulting in decrease oil cut. By 18th minute, water cut has reached $95 \%$. At this point, surfactant-polymer slug has been introduced. Figure 12 shows that there is a decrease in water cut and increased oil cut with time. Also, cumulative oil recovery increases sharply.
A second plot of water cut and cumulative oil versus pore volume injected reflects the similar aspect (Fig. 13).

According to Fig. 12, total oil recovered at the end of water flooding is $24 \mathrm{ml}$. After SP flooding, total oil recovered is $49 \mathrm{ml}$ (after injecting same amount of chase water as in case of surfactant flooding). Thus, the additional recovery using SP flooding is $(49-24)$ / $102=24 \%$. The experimental value shows additional recovery to be $23.45 \%$. A comparison of oil recovery by surfactant and surfactant-polymer flooding in cases of experiment and simulation has been given in Table 3 . 
Fig. 13 Plot of water cut and cumulative oil with pore volumes injected in case of surfactant-polymer flooding

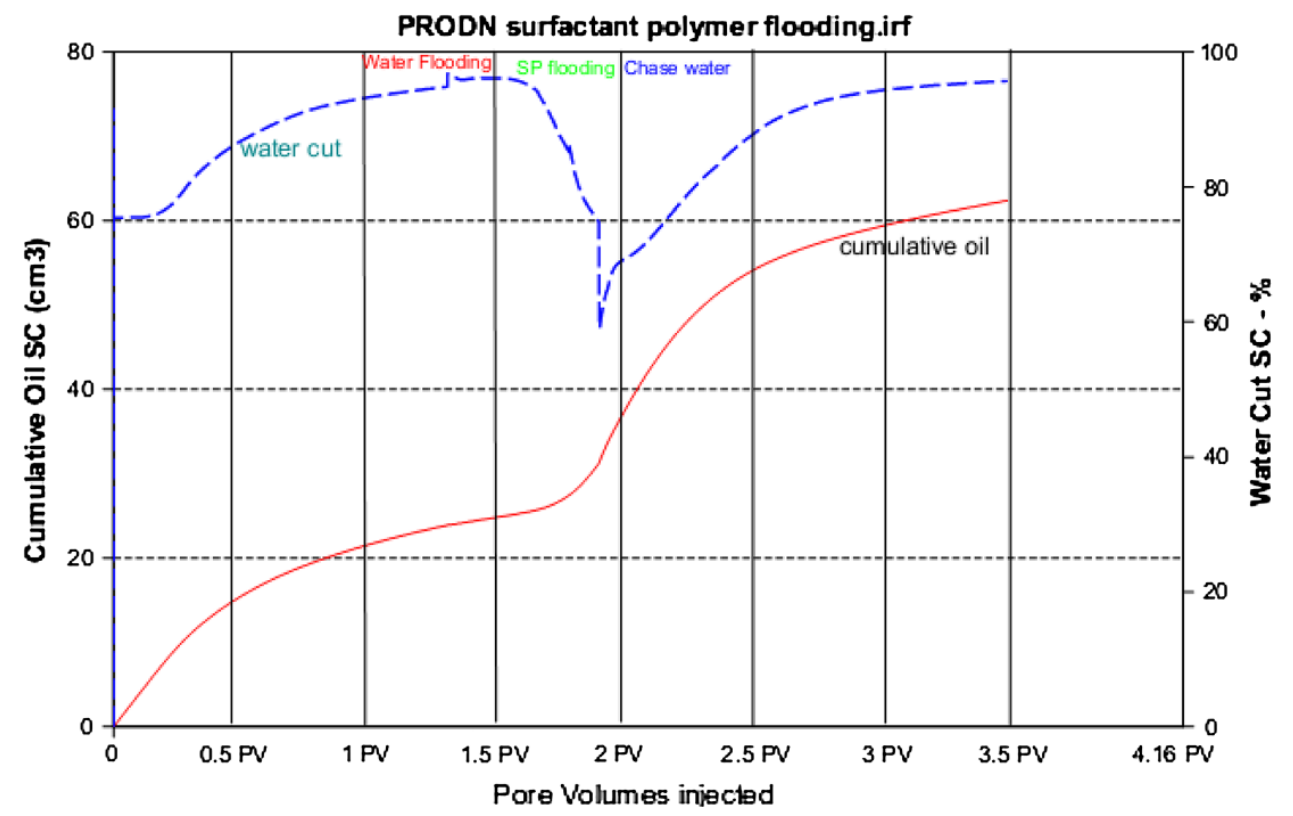

Table 3 Results of oil recovery of surfactant and surfactant-polymer flooding in experiment and simulation

\begin{tabular}{lll}
\hline Flooding agents & \multicolumn{2}{l}{ Additional oil recovery, \% OOIP } \\
\cline { 2 - 3 } & Experimental results & Simulated results \\
\hline Surfactant & 18 & 17.65 \\
Surfactant-polymer & 23.45 & 24 \\
\hline
\end{tabular}

\section{Conclusions}

By utilizing the surfactant and polymer-related simulation capabilities which are currently available in the simulation software, CMG STARS, two sets of experimental data have been modeled and matched using physically realistic input parameters. The first experiment consisted of a surfactant injection which was carried out after water flooding in a sand pack. According to surfactant flooding simulation, the additional recovery after water flooding was found to be $17.65 \%$ which is comparable with the experimental results.

The second experiment was conducted on a different sand pack. It consisted of surfactant polymer flooding. According to chemical flooding simulation, the additional recovery after water flooding was found to be $24 \%$.

The plot of time versus water cut in both situations shows a decrease in water cut whenever surfactant flooding or SP flooding was introduced, thus reflecting inverse relationship between water cut and surfactant or SP flooding.

Also, it was observed that the additional oil recovery in case of surfactant-polymer flooding was greater than when only surfactant was used. This is because of the synergistic contribution of IFT reduction using surfactant and mobility ratio reduction by polymer, thus improving the overall sweep efficiency by a better margin in comparison with surfactant flooding where only IFT reduction is available.

Use of very small quantity of surfactant reduces the surface tension of displacing fluid (water) significantly, which in turn increases the recovery by forming an oil bank. On the other hand, use of polymer increases sweep efficiency by decreasing the mobility ratio.

Acknowledgments The authors gratefully acknowledge the financial assistance provided by University Grant Commission [F. No. 37-203/2009(SR)], New Delhi, to the Department of Petroleum Engineering, Indian School of Mines, Dhanbad, India. Thanks are also extended to all individuals associated with the project.

Open Access This article is distributed under the terms of the Creative Commons Attribution License which permits any use, distribution, and reproduction in any medium, provided the original author(s) and the source are credited.

\section{References}

Austad T, Fjelde I, Veggeland K, Taugbøl K (1994) Physicochemical principles of low tension polymer flood. J Petrol Sci Eng 10:255-269

Bera A, Ojha K, Mandal A, Kumar T (2011) Interfacial tension and phase behavior of surfactant-brine-oil system. Colloid Surf A 383:114-119

Bhuyan D, Lake LW, Pope GA (1990) Mathematical modeling of high-pH chemical flooding. SPE Res Eng 5(2):213-220

Cayias JL, Schechter RS, Wade WH (1976) Modeling crude oils for low interfacial tension. Soc Pet Eng J 16:351-357

Chaipornkaew M, Wongrattapitak K, Chantarataneewat W, Boontaeng T, Opdal ST, Maneeintr K (2013) Preliminary study of insitu combustion in heavy oil field in the North of Thailand. Proc Earth Planet Sci 6:326-334 
Delshad M, Kim DH, Magbagbeola OA, Huh C, Pope GA, Tarahhom F (2008) Mechanistic interpretation and utilization of viscoelastic behavior of polymer solutions for improved polymer-flood efficiency. Paper SPE 113620, presented at the SPE/DOE improved oil recovery symposium held in Tulsa, Oklahoma, USA, 19-23 April. doi:10.2118/113620-MS

Fathi Najafabadi N, Han C, Delshad M, Sepehrnoori K (2009) Development of a three phase, fully implicit, parallel chemical flood simulator. SPE Paper 119002, Presented at SPE Reservoir Simulation Symposium, The Woodlands, TX, 2-4 Feb

Flumerfelt RW, Li X, Cox JC, Hsu WF (1993) A cyclic surfactantbased imbibition/solution gas drive process for low permeability, fractured reservoirs. Paper presented at annual technical conference and exhibition, Houston, TX

Guo SP, Huang YZ (1990) Physical chemistry microscopic seepage flow mechanism. Science Press, Beijing

Han C, Delshad M, Sepehrnoori K, Pope GA (2007) A fully implicit, parallel, compositional chemical flooding simulator. SPE Paper 97217. SPE J 12(3):322-338

Healy RN, Reed RL (1974) Physicochemical aspects of micro emulsion flooding. Soc Petrol Eng J 14:491-501

Hill HJ, Reisberg H, Stegemeier GL (1973) Aqueous surfactant system for oil recovery. J Petrol Technol 25:186-194

Keijzer PPM, De Vries AS (1990) Imbibitions of surfactant solutions. Paper presented at SPE/DOE 7th symposium on enhanced oil recovery, Tulsa, OK

Michels AM, Djojosoeparto RS, Haas H, Mattern RB, Van Der Weg PB, Schulle WM (1996) Enhanced waterflooding design with dilute surfactant concentrations for North Sea conditions. SPE Reserv Eng 11:189-195

Needhan RB, Peter HD (1987) Polymer flooding review. J Petrol Technol 12:1503-1507

Pandey A, Beliveau D, Corbishley D, Kumar MS (2008) Design of an ASP pilot for the Mangala field: laboratory evaluations and simulation studies. Paper SPE 113131, presented at the Indian oil and gas technical conference and exhibition, Mumbai, 4-6 March

Paul GW, Lake LW, Pope GA (1982) A simplified predictive model for micellarpolymer flooding. SPE Paper 10733, Presented at SPE California Regional Meeting, San Francisco, CA, 24-26 March

Pope GA, Nelson RC (1978) Description of an improved compositional micellar/polymer simulator. SPE PAPER 13967. SPE J 18(5):339-354

Santos MD, Neto AD, Mata W, Silva JP (2011) New antenna modelling using wavelets for heavy oil thermal recovering methods. J Petrol Sci Eng 76:63-75

Shandrygin AN, Lutfullin A (2008) Current status of enhanced recovery techniques in the fields of Russia. Paper SPE 115712-MS, presented at SPE annual technical conference and exhibition, Denver, Colorado, 21-24 Sep

Taber JJ, Martin FD, Seright RS (1979) EOR-screening criteria revisited-part 1: introduction to screening criteria and enhanced recovery field projects. SPE Reserv Eng 12:189-198

Vaskas AJ (1996) Optimization of surfactant flooding: an economic approach. Master's thesis, The University of Texas at Austin, TX 